Article

\title{
Impedance, Electrical Equivalent Circuit (EEC) Modeling, Structural (FTIR and XRD), Dielectric, and Electric Modulus Study of MC-Based Ion-Conducting Solid Polymer Electrolytes
}

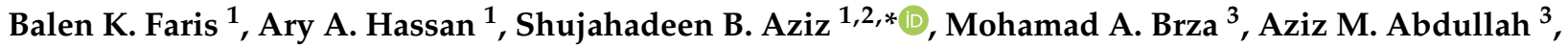 \\ Ari A. Abdalrahman ${ }^{1}$, Ola A. Abu Ali ${ }^{4}$ and Dalia I. Saleh ${ }^{4}$ (D) \\ 1 Hameed Majid Advanced Polymeric Materials Research Lab., Physics Department, College of Science, \\ University of Sulaimani, Qlyasan Street, Kurdistan Regional Government, Sulaimani 46001, Iraq; \\ balen.07001510@univsul.edu.iq (B.K.F.); ary.07001490@univsul.edu.iq (A.A.H.); \\ ari.abdulla@univsul.edu.iq (A.A.A.) \\ 2 Department of Civil Engineering, College of Engineering, Komar University of Science and Technology, \\ Kurdistan Regional Government, Sulaimani 46001, Iraq \\ 3 Medical Physics Department, College of Medicals \& Applied Science, Charmo University, \\ Chamchamal 46023, Sulaimani, Iraq; mohamad.brza@gmail.com (M.A.B.); \\ aziz.abdullah@charmouniversity.org (A.M.A.) \\ 4 Department of Chemistry, College of Science, Taif University, P.O. Box 11099, Taif 21944, Saudi Arabia; \\ o.abuali@tu.edu.sa (O.A.A.A.); daliarawan@yahoo.com (D.I.S.) \\ * Correspondence: shujahadeenaziz@gmail.com
}

check for updates

Citation: Faris, B.K.; Hassan, A.A.; Aziz, S.B.; Brza, M.A.;

Abdullah, A.M.; Abdalrahman, A.A.; Abu Ali, O.A.; Saleh, D.I. Impedance, Electrical Equivalent Circuit (EEC) Modeling, Structural (FTIR and XRD), Dielectric, and Electric Modulus Study of MC-Based Ion-Conducting Solid Polymer Electrolytes. Materials 2022, 15, 170. https://doi.org/10.3390/ma15010170

Academic Editor: Jianbo Yin

Received: 27 October 2021

Accepted: 24 December 2021

Published: 27 December 2021

Publisher's Note: MDPI stays neutral with regard to jurisdictional claims in published maps and institutional affiliations.

Copyright: (C) 2021 by the authors. Licensee MDPI, Basel, Switzerland. This article is an open access article distributed under the terms and conditions of the Creative Commons Attribution (CC BY) license (https:// creativecommons.org/licenses/by/ $4.0 /)$.

\begin{abstract}
The polymer electrolyte system of methylcellulose (MC) doped with various sodium bromide $(\mathrm{NaBr})$ salt concentrations is prepared in this study using the solution cast technique. FTIR and XRD were used to identify the structural changes in solid films. Sharp crystalline peaks appeared at the XRD pattern at 40 and $50 \mathrm{wt} . \%$ of $\mathrm{NaBr}$ salt. The electrical impedance spectroscopy (EIS) study illustrates that the loading of $\mathrm{NaBr}$ increases the electrolyte conductivity at room temperature. The DC conductivity of $6.71 \times 10^{-6} \mathrm{~S} / \mathrm{cm}$ is obtained for the highest conducting electrolyte. The EIS data are fitted with the electrical equivalent circuit (EEC) to determine the impedance parameters of each film. The EEC modeling helps determine the circuit elements, which is decisive from the engineering perspective. The DC conductivity tendency is further established by dielectric analysis. The EIS spectra analysis shows a decrease in bulk resistance, demonstrating free ion carriers and conductivity boost. The dielectric property and relaxation time confirmed the non-Debye behavior of the electrolyte system. An incomplete semicircle further confirms this behavior model in the Argand plot. The distribution of relaxation times is related to the presence of conducting ions in an amorphous structure. Dielectric properties are improved with the addition of $\mathrm{NaBr}$ salt. A high value of a dielectric constant is seen at the low frequency region.
\end{abstract}

Keywords: methylcellulose polymer electrolyte; XRD and FTIR; impedance study; EEC modeling; dielectric study; electric modulus analysis; relaxation processes

\section{Introduction}

The focus on polymers has been further increased with technology and science. However, more limitations have arisen with the enlargement of the latest class of polymers, such as the supply of raw material, synthesis technology, and production cost [1]. Polymer electrolytes (PEs) are macromolecular systems with which ions and protons can transport charge. The majority of typical applications of PEs are in energy conversion devices and storage devices such as supercapacitors (SCs), fuel cells, and batteries [2-6]. These materials were first mentioned by Fenton et al. in 1973 [2]. PEs consist of dissolved salts in polymer matrices with high molecular mass [7-9]. These materials are better than the traditional liquid electrolytes. For example, an ionic-conducting phase 
has a transport property compared with other liquid ionic solutions, in addition to being lightweight, having relatively high ionic conductivity, solvent-free, flexibility, and thin film forming capability. In addition, PEs are safe and free from the problem of electrolyte leakage $[7,9,10]$. The first ion-conducting polymer was poly(ethylene oxide) (PEO) that incorporated with alkali metal salts in 1973 [11]. A DC conductivity of $5.817 \times 10^{-7} \mathrm{~S} / \mathrm{cm}$ was obtained with $30 \mathrm{wt} . \%$ ammonium tetrafluoroborate $\left(\mathrm{NH}_{4} \mathrm{BF}_{4}\right)$ in the chitosan:PEO (CS:PEO) polymer blend [12]. Adding $30 \mathrm{wt} . \% \mathrm{NH}_{4} \mathrm{BF}_{4}$ into a CS:potato starch (PS) provided the conductivity $3.07 \times 10^{-8} \mathrm{~S} / \mathrm{cm}$ [13]. Salehan et al. [14] reported that the loading of $2 \mathrm{wt} . \%$ aluminium oxide $\left(\mathrm{Al}_{2} \mathrm{O}_{3}\right)$ into a corn starch (CS):lithium iodide (LiI) provided a conductivity of $(6.73 \pm 0.78) \times 10^{-4} \mathrm{~S} / \mathrm{cm}$. Shetty et al. [15] documented that the loading of $20 \mathrm{wt} . \%$ sodium bromide $(\mathrm{NaBr})$ into carboxymethyl cellulose (CMC) provided a conductivity of $\sim 5.15 \times 10^{-4} \mathrm{~S} / \mathrm{cm}$.

From the necessary viewpoint, ionic conduction in solid polymer electrolytes (SPEs) is not well understood. This is because the property of ion transport relies on many factors, including salt concentration, degree of salt dissociation, degree of ion aggregation, the dielectric constant of host polymer, and polymer chains mobility [8,10,16-19].

The polymer electrolyte dielectric analysis delivers additional information even though these materials possess an elevated conductivity value. Thus, the phenomena of dielectric relaxation study are an influential tool for comprehending ion transport behavior and gaining information of molecular/ionic interaction in polymer electrolytes [20].

Dielectric measurements, for example dielectric loss and constant, provide valuable insight into polymers' physical and chemical properties. These properties can be dramatically prejudiced by incorporating other polymers or a filler to the polymer [21,22]. More studies were performed on Li salt interacted PE, but fewer efforts were made on PE-based sodium interacted films. Using sodium in PE has more advantages over its lithium counterpart. Sodium is more abundant and cheaper than lithium [23]. Hence, the sodium-ion battery has drawn more attention as the next generation secondary battery as it is $40 \%$ cheaper than a lithium-ion battery. Fuentes et al. [24] documented that lithium salt PEs are the most suitable and, therefore, the most commonly used in the new battery generation design. However, their study found that $\mathrm{Na}^{+}$ions produce a higher ionic conductivity or at least a similar conductivity to $\mathrm{Li}^{+}$ions in the same primary material. This provided an outstanding opportunity to use $\mathrm{Na}^{+}$ions rather than lithium in constructing a new battery generation, improving conductivity, and ensuring widespread supply. $\mathrm{NaBr}$ has a small lattice energy of $747 \mathrm{~kJ} / \mathrm{mol}$, which is marginally lower than $\mathrm{NaCl}(786 \mathrm{~kJ} / \mathrm{mol})$ as the size of $\mathrm{Cl}^{-}(167 \mathrm{pm})$ is smaller than the size of $\mathrm{Br}^{-}$(182 pm) [12,25]. The salts lattice energy, such as sodium salts used in PEs, can considerably impact the conductivity of the synthesized electrolyte. Two factors determine the salts lattice energy. The first is the charge of the ions and the second is their size. The charge ion raises the lattice energy of the salt, whereas the ion size decreases the salt lattice energy.

Railanmaa et al. [26] presented gelatin gel electrolyte properties in the printed supercapacitor, and they studied the mechanical and electrical behaviors of the devices. The authors focused on gel performance. The gel electrolyte performance was similar to an aqueous liquid electrolyte (LE) with a similar salt as the ionic conductor with respect to the main features: equivalent series resistance, capacitance, and leakage current. With a $2 \mathrm{M} \mathrm{NaCl}$ gel electrolyte, the performance of electrical equivalent to that of a $1 \mathrm{M} \mathrm{LE}$ was obtained, and the devices endured bending down to a $10 \mathrm{~mm}$ radius [26].

In this research, the effect of $\mathrm{NaBr}$ salt on the dielectric property of MC-based electrolytes was studied. The structural behaviors of the films were examined. The relaxation process was analyzed in more detail with respect to electric modulus and Tan $\delta$ spectra. From the viewpoint of engineering, materials with a small value of Tan $\delta$ are more vital for electronics and devices application. 


\section{Experimental Details}

\subsection{Raw Materials and Sample Preparation}

Both MC (4000 cp) and $\mathrm{NaBr}(102.894 \mathrm{~g} / \mathrm{mol})$ were supplied by Sigma-Aldrich and used in this research. The solid polymer preparations were carried out in aqueous solution using distilled water. It comprised dissolution of $1 \mathrm{~g}$ of $\mathrm{MC}$ powder in $100 \mathrm{~mL}$ of $1 \%$ acetic acid by stirring using a magnetic stirrer for around $24 \mathrm{~h}$ at room temperature. The stirring continued until homogeneous clear and viscose solutions were obtained. In the preparation of $\mathrm{MC} / \mathrm{NaBr}$ SPE system, different quantities of $\mathrm{NaBr}(10,20,30,40$, and 50 wt.\%) were loaded into a series of solutions of solid polymers with continuous stirring. This series of solutions was cast into Petri dishes to dry at room temperature for films to form. The films were transferred into a desiccator with silica gel desiccants to keep dry. Table 1 summarizes the main components of the prepared samples.

Table 1. The elements of SPE films.

\begin{tabular}{cccc}
\hline Designation & NaBr (wt. \%) & MC (g) & NaBr (g) \\
\hline MCNAB1 & 10 & 1.00 & 0.1111 \\
MCNAB 2 & 20 & 1.00 & 0.2500 \\
MCNAB 3 & 30 & 1.00 & 0.4286 \\
MCNAB 4 & 40 & 1.00 & 0.6666 \\
MCNAB 5 & 50 & 1.00 & 1.0000 \\
\hline
\end{tabular}

\subsection{Electrochemical Impedance Spectroscopy (EIS) Technique}

At ambient temperature, the EIS of the prepared films was acquired using an HIOKI 3531 Z LCR Hi-tester within a frequency ranged between 50 and $5000 \mathrm{kHz}$. The LCR meter was hyphenated to a computer where the imaginary and real parts of the EIS were displayed. The films were sandwiched between 2 identical circular stainless steel electrodes in the form of discs with a $2 \mathrm{~cm}$ diameter and sandwiched under spring pressure to ensure the desired contact.

\section{Results and Discussion}

\subsection{FTIR and XRD Analysis}

Figure 1a,b shows the FTIR spectra of each film. Hydrogen bond creation in MC electrolyte is explained by IR spectroscopy as hydrogen bonding changes the stretching vibration frequency $[27,28]$. The hydroxyl band in pure MC and MCNAB electrolyte films is related to the wavenumber ranged from 3435 to $3447 \mathrm{~cm}^{-1}$, while the ether band emerged at 1047 and $1113 \mathrm{~cm}^{-1}$ [29], and the absorption bands shifted and intensity decreased in the electrolyte films. The absorption bands at 1419, 1609, 2927, and $3418 \mathrm{~cm}^{-1}$ in the MCNAB electrolyte films are related to the symmetrical stretching vibration of COO-, asymmetrical stretching vibration of $\mathrm{COO}-$, aliphatic $\mathrm{C}-\mathrm{H}$, and $\mathrm{O}-\mathrm{H}$, respectively [30]; however, the intensity of the peaks decreased and shifted from MCNAB1 to MCNAB5. The peaks related to $\mathrm{C}-\mathrm{H}$ stretching vibration at $2901 \mathrm{~cm}^{-1}, \mathrm{O}-\mathrm{H}$ stretching vibration at $3447 \mathrm{~cm}^{-1}, \mathrm{C}-\mathrm{O}$ stretching vibration from asymmetric oxygen bridge between 1057 and $1113 \mathrm{~cm}^{-1}, \mathrm{C}-\mathrm{O}$ carbonyl stretching vibration from the glucose of the cellulose at $1635 \mathrm{~cm}^{-1}$, and $\mathrm{O}-\mathrm{CH}_{3}$ stretching vibration at $938 \mathrm{~cm}^{-1}$ are seen in pure MC [27]. In the case of MCNAB electrolyte films, these peaks shift and intensity decreases, while addition of 50 wt.\% NaBr causes it to decrease noticeably as revealed in Figure 1b. Small absorption peaks between 1247 and $1448 \mathrm{~cm}^{-1}$ are connected to $\mathrm{C}-\mathrm{H}$ bending vibration of MC. Small bands between 478 and $648 \mathrm{~cm}^{-1}$ are related to $\mathrm{C}-\mathrm{H}$ vibration [31]. These bands shifted in their position and decreased in intensity in the case of the MCNAB electrolyte films. The free or unbounded hydroxyl group are related to 3649 to $3511 \mathrm{~cm}^{-1}$. The hydrogen-bound hydroxyl group existence caused a shift of absorption to lower frequency while the intensity was increased and the band widened, and an asymmetrical peak emerged. The hydroxyl absorption measures the interaction of hydrogen bonding and the hydrogen bond strength 
in the polymer. The MC spectrum region that is relevant is between 3799 and $3001 \mathrm{~cm}^{-1}$, and the spectrum was inferred in terms of hydroxyl stretching at $3459 \mathrm{~cm}^{-1}$ [28]. The $950-1250 \mathrm{~cm}^{-1}$ region is more informative from the perspective of the issues solved herein. The $947-1249 \mathrm{~cm}^{-1}$ range includes a complex robust absorption band of MC which is owing to $\mathrm{C}-\mathrm{O}$ bond stretching vibration in the spectra of cellulose and its ether [32].
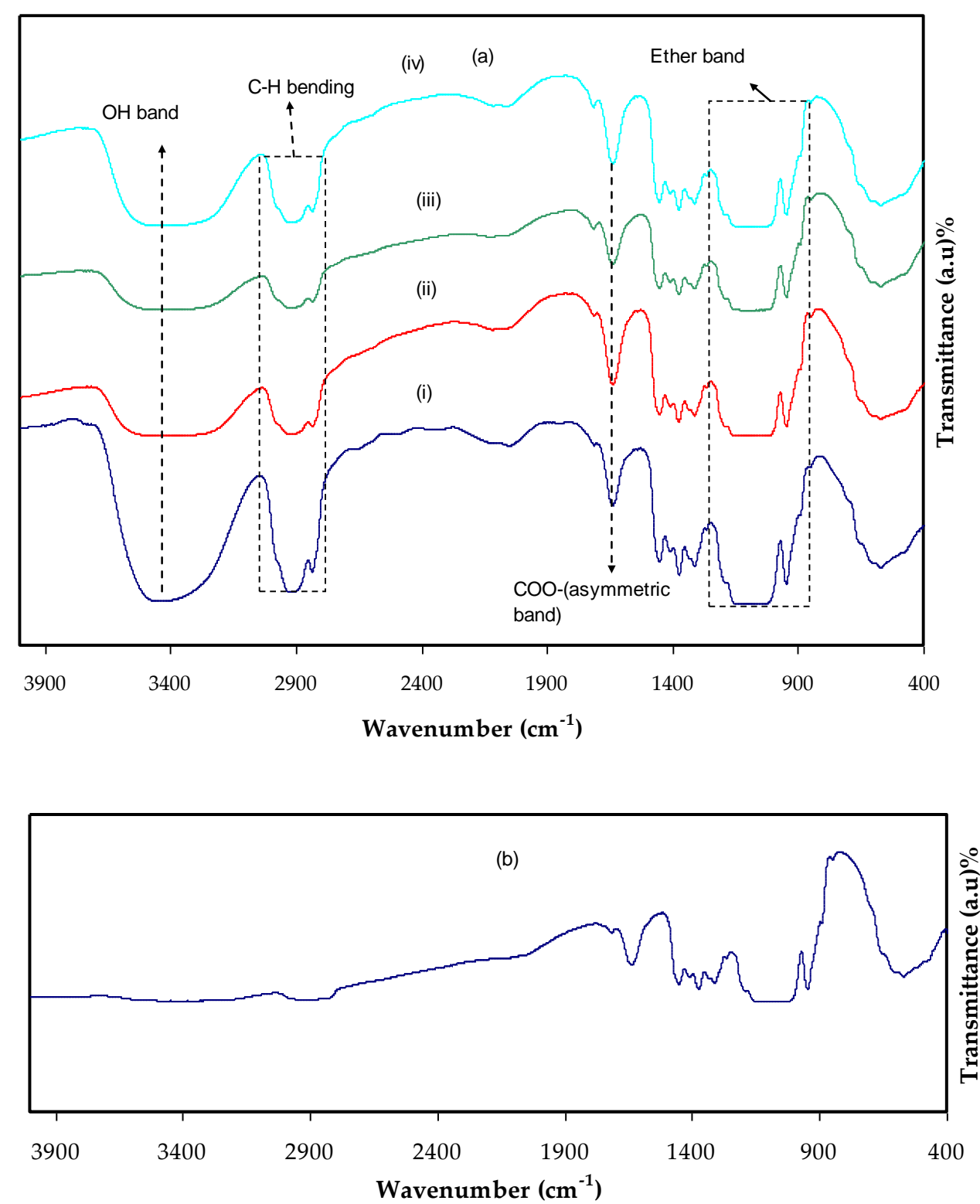

Figure 1. FTIR spectra at a wave number between $400 \mathrm{~cm}^{-1}$ to $4000 \mathrm{~cm}^{-1}$ (a) for (i) MCNAB1, (ii) MCNAB2, (iii) MCNAB3, and (iv) MCNAB4, and (b) for MCNAB5 electrolyte films.

Figure 2a,b shows the XRD pattern of $\mathrm{MC}$ and $\mathrm{NaBr}$ salt, and MC-doped samples are shown in Figure 3. It was mentioned that the wide crystalline hump that appeared at around $2 \theta$ between $19^{\circ}$ and $21^{\circ}$ relates to the intermolecular hydrogen bonding and shows a short distance order of the film chains in MC [33,34]. It is seen that for 20 and $30 \mathrm{wt} . \%$ of $\mathrm{NaBr}$, the intensity decreased, the broadening increased, and some new crystalline peaks emerged. This broadening is due to the distraction of the crystalline nature of the polymer by loading $\mathrm{NaBr}$ [34]. The XRD analysis revealed an increase in the amorphous structure in the MC:NaBr films, whereas the MCNAB4 and MCNAB54 samples' spectra revealed several high-intensity peaks related to the undissolved salts in these samples and their leakage through the film surface. As displayed in Figures $2 b$ and 3, the XRD peaks of 
the undissolved salt appeared in the electrolyte films. The XRD results are in agreement with EIS results in the next section as the conductivity decreased for the MCNAB4 and MCNAB54 samples.
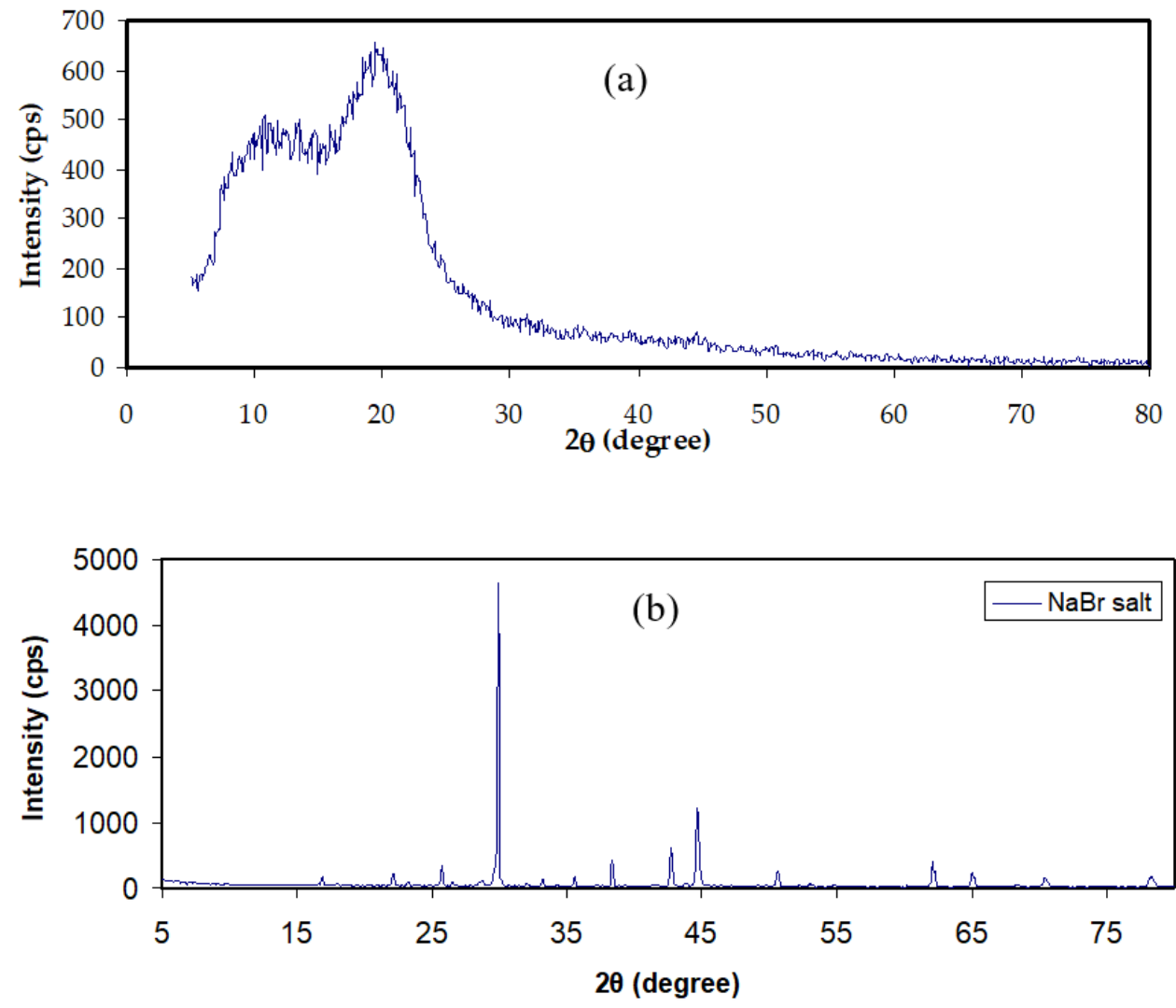

Figure 2. XRD pattern of (a) neat MC film and (b) $\mathrm{NaBr}$ salt.

\subsection{Study of Impedance Plots}

Indispensable marks which differentiate PEs from ionic conductors obtained by dissolving salts in small molar mass solvents begin from the cation motion mechanism. The electrical impedance responses, including the $\mathrm{Z}^{\prime}$ vs. $\mathrm{Z}^{\prime \prime}$, for the MC:NaBr electrolyte films are displayed in Figure $4 \mathrm{a}-\mathrm{e}$. The EEC as a modeling is regularly used in the impedance spectroscopy analysis, because it is straightforward and explains a broad picture [35]. The experimental impedance responses can be explained with respect to the EEC that comprises bulk resistance $\left(R_{b}\right)$ and the constant phase elements of CPE1 and CPE2 for the charge carriers within the sample as exhibited in insets of Figure 4.

The elevated frequency section is the location of $R_{b}$ and CPE1 responses, and at the low frequency area, CPE2 appears. The CPE2 response results from the double layer capacitance between the electrodes and polymer electrolyte at the low frequency region. It is well known that in a definite system, the CPE term is further often used in equivalent circuits in place of the perfect capacitor. This nomination is owed because, in SPE, there is pseudocapacitor behavior dissimilar from that of a pure or idyllic capacitor in an ideal semicircular model [36]. 

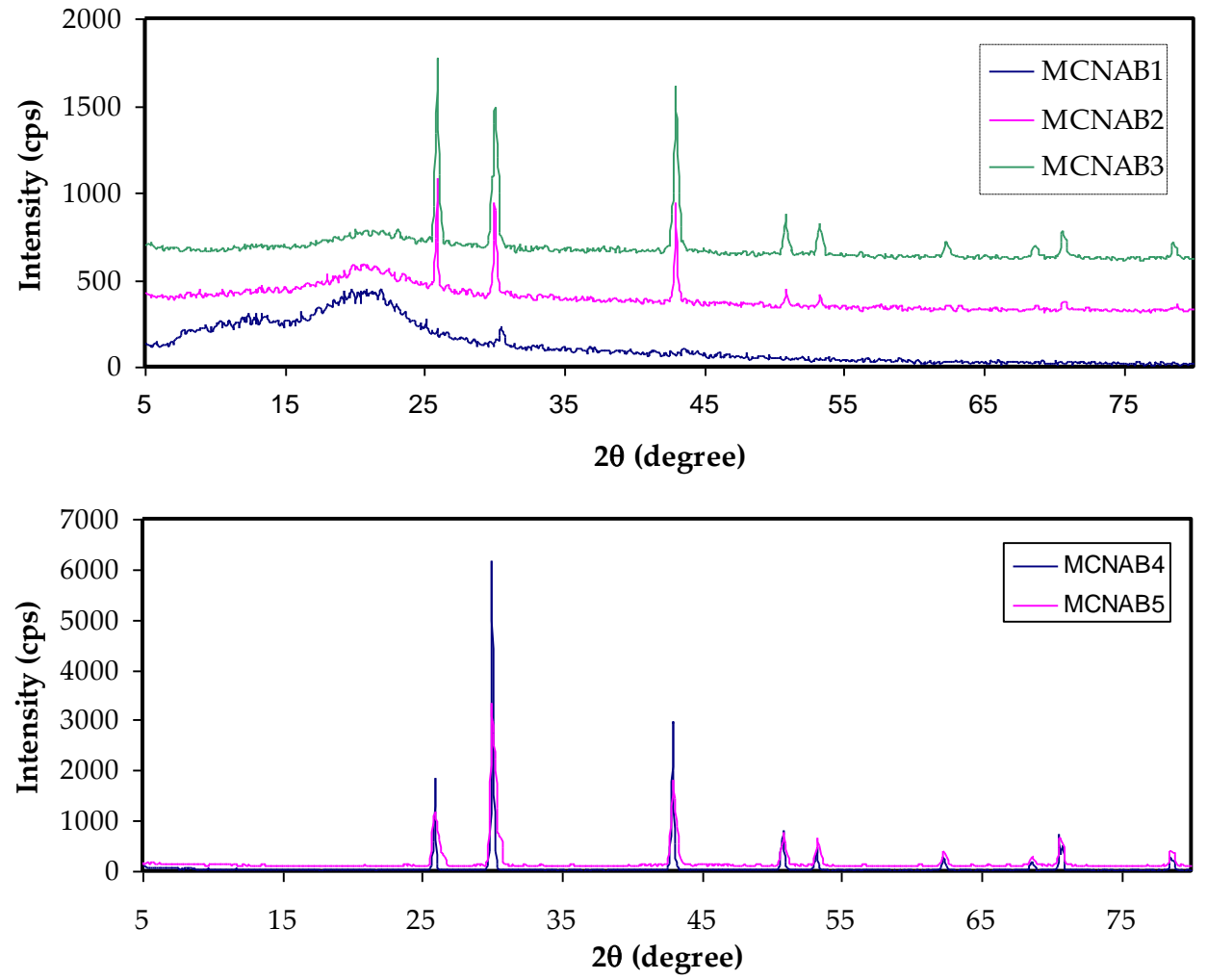

Figure 3. XRD pattern of $\mathrm{MC}: \mathrm{NaBr}$ solid electrolyte films.

Figure 4a-e exhibits the impedance responses and corresponding ECs for all blend samples. In Figure 4a, a complex impedance response is shown that consists of a depressing semicircle at the region of high frequency. The equivalent circuit is expressed as a parallel arrangement of $R_{b}$ and CPE in Figure 4a. Based on experimental results, the equivalent circuit is expressed as a parallel combination of $R_{b}$ and bulk capacitance (CPE) in series with another CPE originating from the tilted point area as presented in Figure $4 \mathrm{~b}-\mathrm{e}$. The mathematical basis of impedance of $Z_{C P E}$ is shown below [37-39]:

$$
Z_{C P E}=\frac{\cos (\pi n / 2)}{Y_{m} \omega^{n}}-j \frac{\sin (\pi n / 2)}{Y_{m} \omega^{n}}
$$

where $Y_{m}$ is the CPE capacitance, angular frequency is referred by $\omega$, and $n$ is the measure of extent of the deviation of the plot from the imaginary axis. Herein, the $Z_{r}$ and $Z_{i}$ of complex impedance $\left(Z^{*}\right)$ in the corresponding circuit (inset of Figure $4 a$ ) is shown below:

$$
\begin{aligned}
& Z_{r}=\frac{R_{1}+R_{1}^{2} Y_{1} \omega^{n 1} \cos \left(\pi n_{1} / 2\right)}{1+2 R_{1} Y_{1} \omega^{n_{1}} \cos \left(\pi n_{1} / 2\right)+R_{1}^{2} Y_{1}^{2} \omega^{2 n_{1}}} \\
& Z_{i}=\frac{R_{1}^{2} Y_{1} \omega^{n_{1}} \sin \left(\pi n_{1} / 2\right)}{1+2 R_{1} Y_{1} \omega^{n_{1}} \cos \left(\pi n_{1} / 2\right)+R_{1}^{2} Y_{1}^{2} \omega^{2 n_{1}}}
\end{aligned}
$$

Herein, the $Z_{r}$ and $Z_{i}$ of $Z^{*}$ in the EC (inset of Figure $4 \mathrm{~b}-\mathrm{e}$ ) is shown below:

$$
\begin{aligned}
& Z_{r}=\frac{R_{1}+R_{1}^{2} Y_{1} \omega^{n 1} \cos \left(\pi n_{1} / 2\right)}{1+2 R_{1} Y_{1} \omega^{n_{1}} \cos \left(\pi n_{1} / 2\right)+R_{1}^{2} Y_{1}^{2} \omega^{2 n_{1}}}+\frac{\cos \left(\pi n_{2} / 2\right)}{Y_{2} \omega^{n_{2}}} \\
& Z_{i}=\frac{R_{1}^{2} Y_{1} \omega^{n_{1}} \sin \left(\pi n_{1} / 2\right)}{1+2 R_{1} Y_{1} \omega^{n_{1}} \cos \left(\pi n_{1} / 2\right)+R_{1}^{2} Y_{1}^{2} \omega^{2 n_{1}}}+\frac{\sin \left(\pi n_{2} / 2\right)}{Y_{2} \omega^{n_{2}}}
\end{aligned}
$$



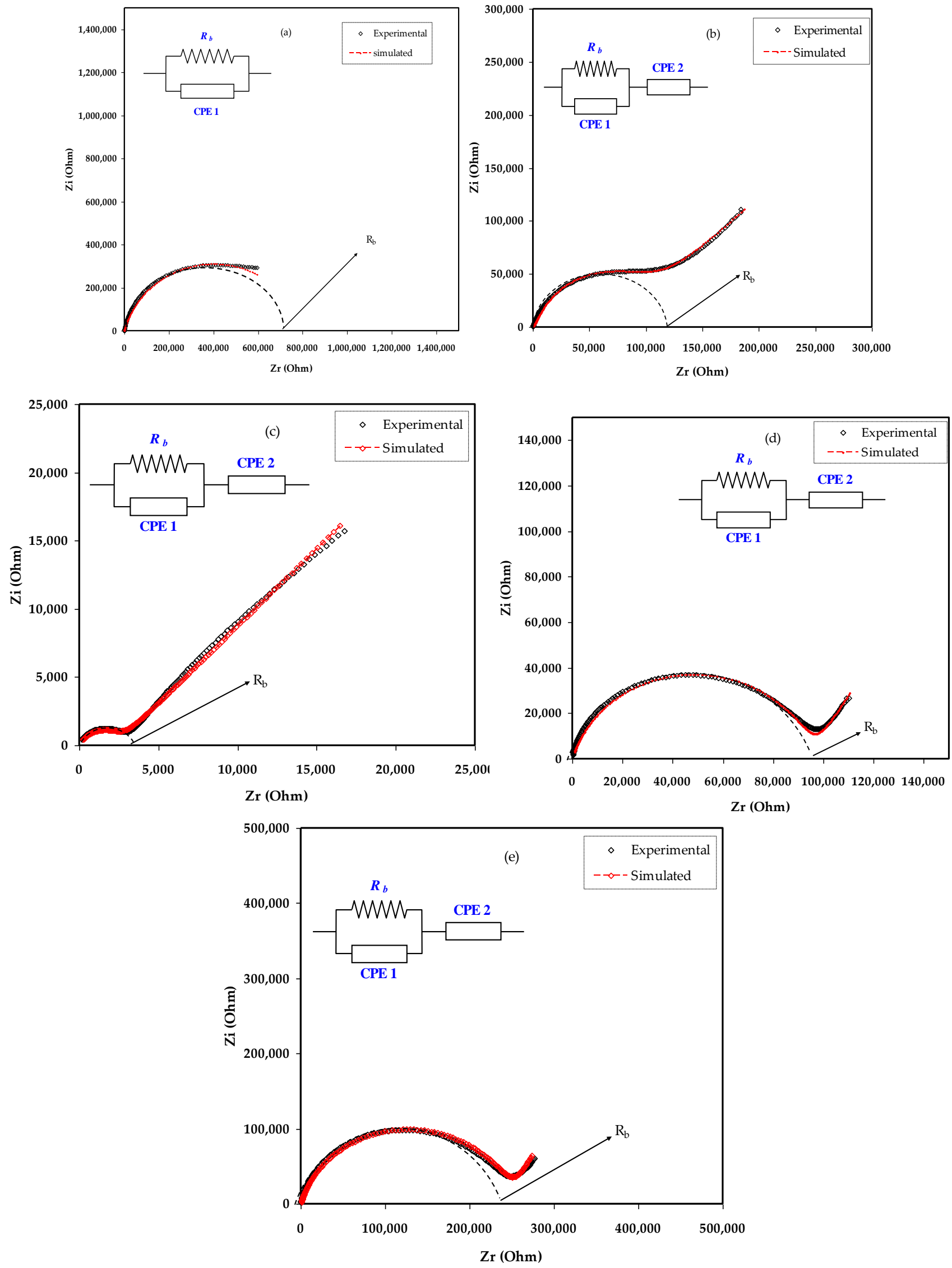

Figure 4. Experimental and fitting (EEC) impedance (Nyquist) plots for (a) MCNAB 1, (b) MCNAB 2, (c) MCNAB 3, (d) MCNAB 4, and (e) MCNAB 5 samples. 
Table 2 presents all the parameters extracted from the fitting of the impedance plots using ECs. The $R_{b}$ in the equivalent circuit represents the bulk resistance, as presented in the inset of Figure 4 . The $R_{b}$ value can be extracted from the figure by intersecting the semicircle with the $Z_{r}$ axis of the spectrum, as presented in Table 2. Given the $R_{b}$ and the film thickness, one can measure the DC conductivity using Equation (6) $[13,40]$,

$$
\sigma_{d c}=\left(\frac{1}{R_{b}}\right) \times\left(\frac{t}{A}\right)
$$

where $t$ stands for the film thickness and the area of the electrodes is represented by $A$. The DC conductivity and $R_{b}$ values of the films are presented in Table 2.

Table 2. The parameters of the circuit elements of the films at room temperature.

\begin{tabular}{ccccccc}
\hline Sample & $\mathbf{n 1}(\mathbf{R a d})$ & $\mathbf{n 2}(\mathbf{R a d})$ & $\mathbf{Y 1} \mathbf{( F )}$ & $\mathbf{Y 2} \mathbf{( F )}$ & $\mathbf{R}_{\mathbf{b}}$ (Ohm) & Conductivity (S/cm) \\
\hline MCNAB 1 & 0.84 & & $1.59 \times 10^{-9}$ & & $8.00 \times 10^{5}$ & $1.93 \times 10^{-8}$ \\
MCNAB 2 & 0.90 & 0.50 & $1.25 \times 10^{-9}$ & $2.56 \times 10^{-7}$ & $8.00 \times 10^{4}$ & $1.93 \times 10^{-7}$ \\
MCNAB 3 & 0.83 & 0.54 & $3.33 \times 10^{-9}$ & $1.43 \times 10^{-6}$ & $2.30 \times 10^{3}$ & $6.71 \times 10^{-6}$ \\
MCNAB 4 & 0.83 & 0.67 & $4.00 \times 10^{-10}$ & $4.00 \times 10^{-7}$ & $9.50 \times 10^{4}$ & $1.62 \times 10^{-7}$ \\
MCNAB 5 & 0.85 & 0.73 & $3.33 \times 10^{-10}$ & $1.37 \times 10^{-7}$ & $2.48 \times 10^{5}$ & $6.22 \times 10^{-8}$ \\
\hline
\end{tabular}

Li et al. [41] prepared an organic-inorganic reticular PE. Isocyanate connects PEO molecular chains and fumed silica. The PEO-TDI-SiO $\mathrm{SPEs}_{2}$ developed can considerably have increased conductivity of $0.12 \mathrm{mS} \mathrm{cm}^{-1}$ at room temperature. This is due to the fact that the $\mathrm{TDI}-\mathrm{SiO}_{2}$ nanoparticles prevent crystallization of the polymer that offers more Li-ion transport pathways.

\subsection{Dielectric and Electric Modulus Analysis}

The most effective method for determining the increase in the free ions density in the PEs, which results in increased conductivity, is to determine the dielectric property [42]. The ion transport process relies powerfully on a few factors; the salt dissociation degree and its concentration, the dielectric constant $\left(\epsilon_{r}\right)$ of polymer, the extent of ion agglomeration, and polymer chains mobility. To better understand conductivity processes, it is necessary to consider the dielectric properties of ionically conducting polymer electrolytes [20]. A unique aspect of PEs is that ion journey occurs lacking long-range displacement of the solvent. Despite serious research, the method of ionic conductivity in polymer electrolytes is still not extensively discussed. Ion transport in PEs is an intricate process counting ion movement, local movement of the polymer segment, and intra- and inter polymer transport among ion coordination sites. One extra vital note is that the $\varepsilon_{r}$ and $\varepsilon_{i}$ parts increase with decreasing frequency. The $\varepsilon_{r}$ and $\varepsilon_{i}$ are revealed in Figures 5 and 6 . The relatively high values of $\varepsilon_{r}$ and $\varepsilon_{i}$ at the stumpy frequency region are due to the contribution of electrode polarization at the interfacial region to the impedance of the samples $[43,44]$. On the one hand, a high involvement of charge accretion at the electrodes-electrolytes interfaces occurs at the low frequency. On the other hand, the periodic setbacks of the electric field (EF) happen rapidly where there is no overload of diffusion of ion in the field direction at the high frequencies. Therefore, the polarization from charge build-up diminishes, resulting in a lesson in both the $\varepsilon_{r}$ and $\varepsilon_{i}$ as shown in Figures 5 and 6 [43]. 


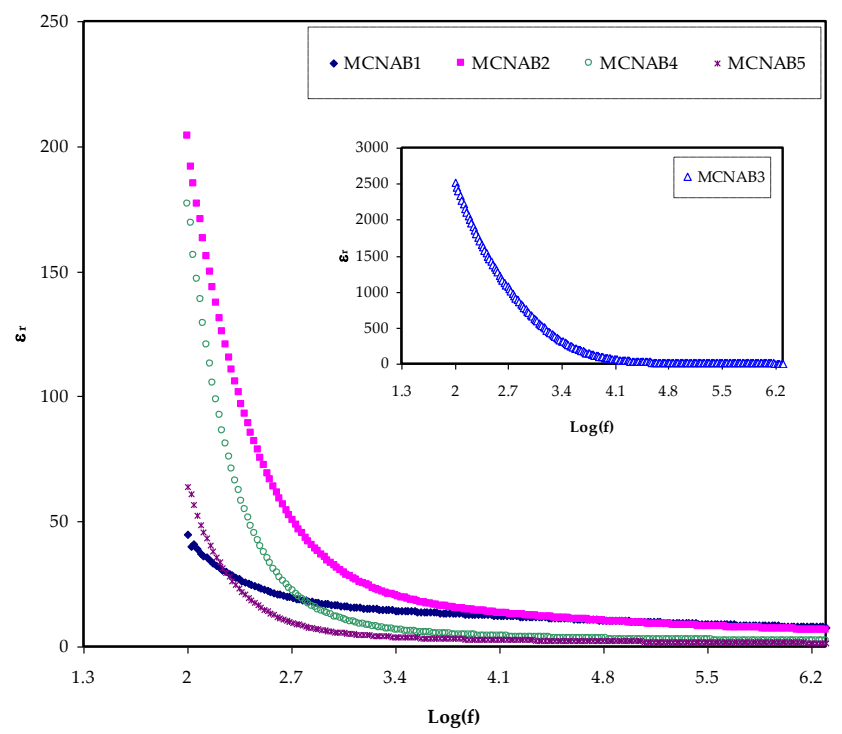

Figure 5. $\varepsilon_{r}$ against frequency at room temperature for each sample.

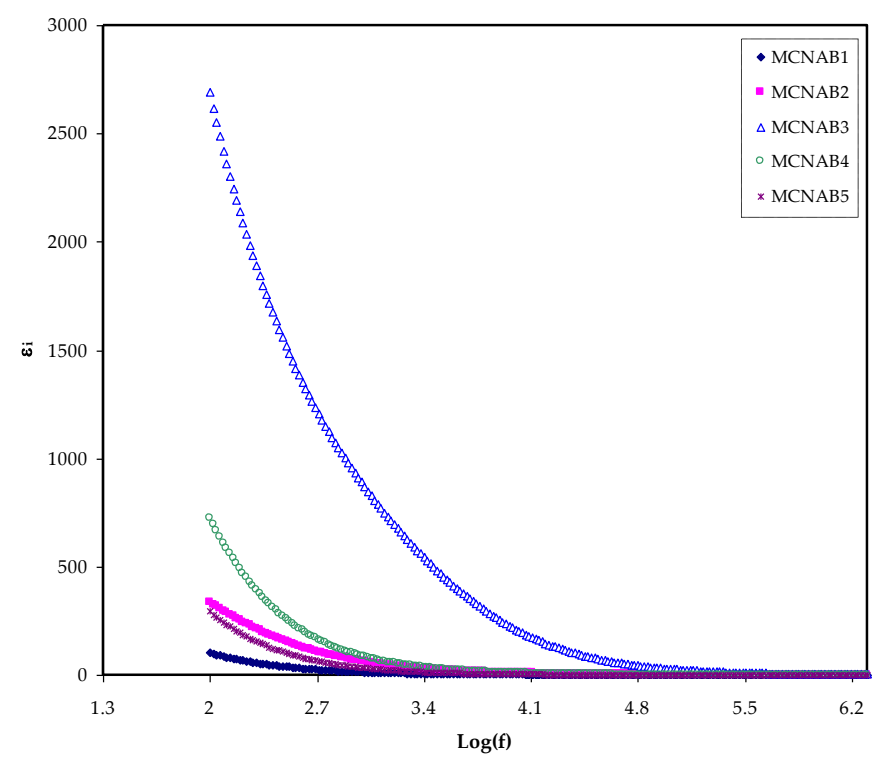

Figure 6. $\varepsilon_{i}$ against frequency at room temperature for each sample.

In the study of dielectric relaxation, one can understand the performance of PEs. Therefore, it is helpful to use a broad frequency range during dielectric relaxation measurements to deal with dipole relaxation in polymeric materials [37]. From the $Z_{r}$ and $Z_{i}$ parts of $Z^{*}$, and the ones of complex electric modulus $\left(M^{*}\right)$ and complex permittivity $\left(\varepsilon^{*}\right)$ can be calculated, using the following relationships $[17,18,37,45-47]$,

$$
\begin{gathered}
\varepsilon_{r}=\frac{Z_{i}}{\omega C_{o}\left(Z_{r}^{2}+Z_{i}^{2}\right)} \\
\varepsilon_{i}=\frac{Z_{r}}{\omega C_{o}\left(Z_{r}^{2}+Z_{i}^{2}\right)} \\
M_{r}=Z_{i} C_{o} \omega \\
M_{i}=Z_{r} C_{o} \omega
\end{gathered}
$$


where the real part and imaginary part of $M^{*}$ are symbolized as $M_{\mathrm{r}}$ and $M_{\mathrm{i}}$ and the dielectric constant and dielectric loss are symbolized as $\varepsilon_{r}$ and $\varepsilon_{i}$, correspondingly. Here, $C_{o}$ refers to the vacuum capacitance under study, which is obtained from $\varepsilon_{0} \mathrm{~A} / \mathrm{t}$ (where $A$ and $t$ are the area and thickness of each film, respectively), and $\omega$ is the angular frequency which is equal to $2 \pi f$, where $f$ is the frequency in Hz.

It is seen in Figure 7 with the loading of $30 \mathrm{wt} . \% \mathrm{NaBr}$ into the MC polymer, the dielectric constant has the highest value due to more free ions and this modification is also seen in the inset of Figure 5. The dielectric constant is decreased at $40 \mathrm{wt} . \%$ and $50 \mathrm{wt} . \%$ $\mathrm{NaBr}$ due to ion association as shown in Figure 7. The $\varepsilon_{r}$ and $\varepsilon_{i}$ values are determined using Equations (7) and (8).

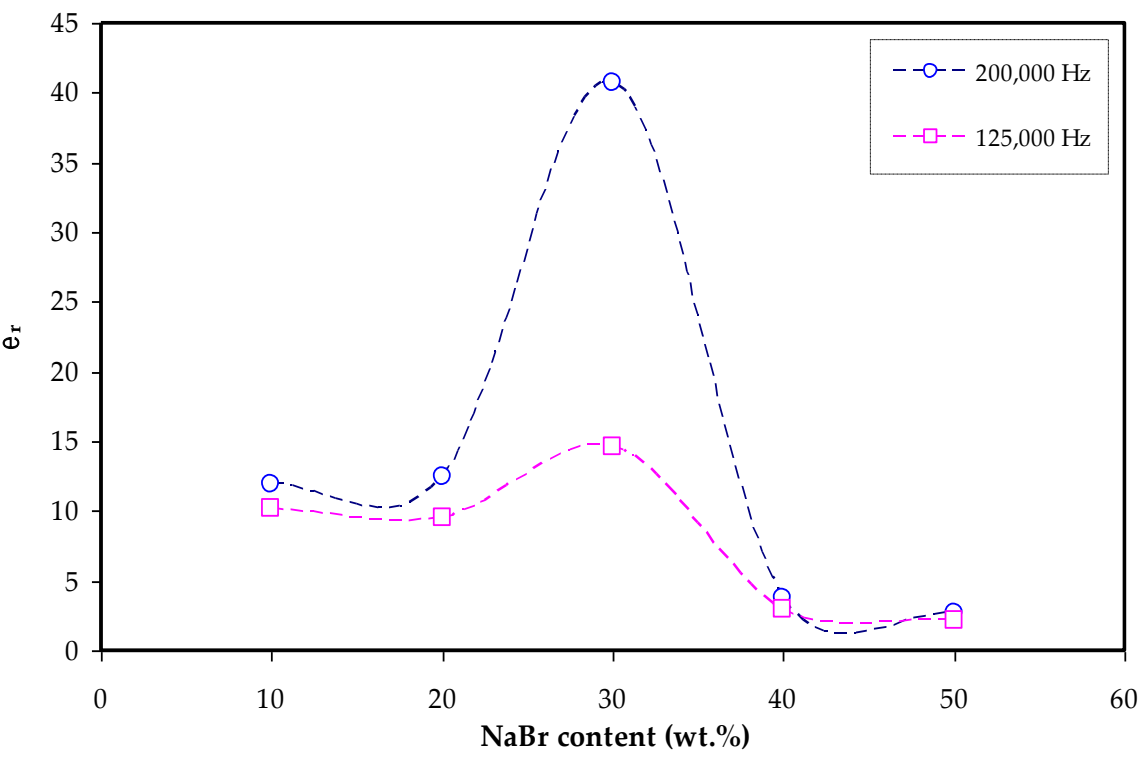

Figure 7. $\varepsilon_{r}$ (at 200,000 and $125,000 \mathrm{~Hz}$ ) vs. NaBr concentration.

Furthermore, the dielectric loss tangent $(\tan \delta)$ was obtained for each electrolyte to comprehend the electrolytes relaxation mechanisms. The $\tan \delta$ is a ratio between energy dispersed and energy stored in an EF called the dissipation factor [48]. The $\tan \delta$ is obtained using Equation (11) [48].

$$
\tan \delta=\frac{\varepsilon_{i}}{\varepsilon_{r}}
$$

The relaxation mechanisms of PEs are specifically investigated using loss tangent peaks. The polymer electrolytes dipoles are explained on the basis of dielectric relaxation [37,49]. Figure 8 indicates the loss $\tan \delta$ dielectric relaxation versus frequency for all films. In Figure 8, the peak of the tangent delta is shifted to the high frequency side of the loss tangent peak, indicating that the relaxation process does not occur in the electrolyte. It is a well-known fact that the permanent dipole or induced dipoles are responsible for conductivity and dielectric relaxation peak to appear in the graph [37,49]. The peaks in Figure 8 illustrate the ion dynamics translation associated with the conductivity relaxation of ions. The $\tan \delta$ increased when the frequency is increased as a result of the active element (ohmic) dominant in comparison with the capacitive reactive element. Following that, the $\tan \delta$ achieves a maximum and then decreases at a high frequency due to the active element independence and the reactive element's dominance [50]. The electrolyte relaxation process presented by the $\tan \delta$ plot indicates the non-Debye behavior of the sample [51].

Moreover, the $\tan \delta$ value located at the maximum frequency is denoted as the $\tan \delta$ maximum $\left(\tan \delta_{\max }\right)$ value that is used to determine the relaxation peak angular frequency $\left(\omega_{\text {peak }}\right)$. Thus, the electrolytes' relaxation time $(\tau)$ is calculated by the reciprocal of $\omega_{\text {peak }}$ $\left(1 / \omega_{\text {peak }}\right)$. The measured $\tau$ values against $\mathrm{NaBr}$ concentrations are shown in Figure 9. 


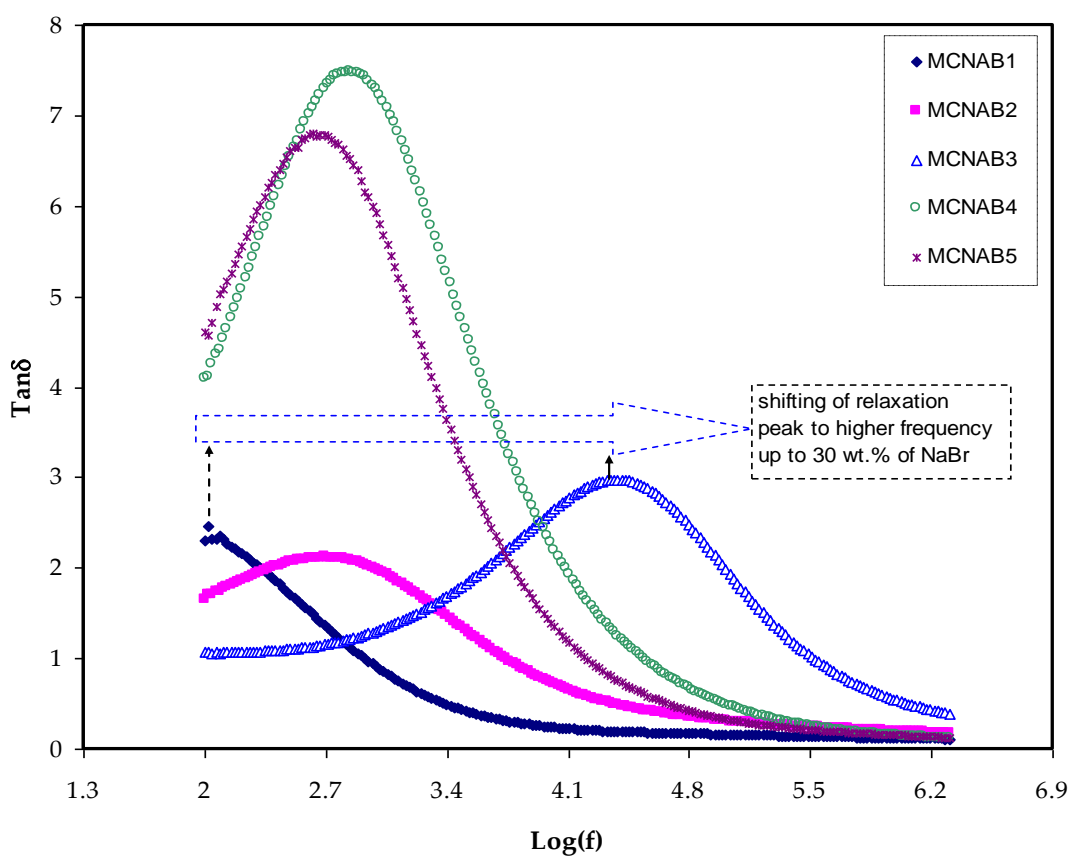

Figure 8. The $\tan \delta$ for the samples.

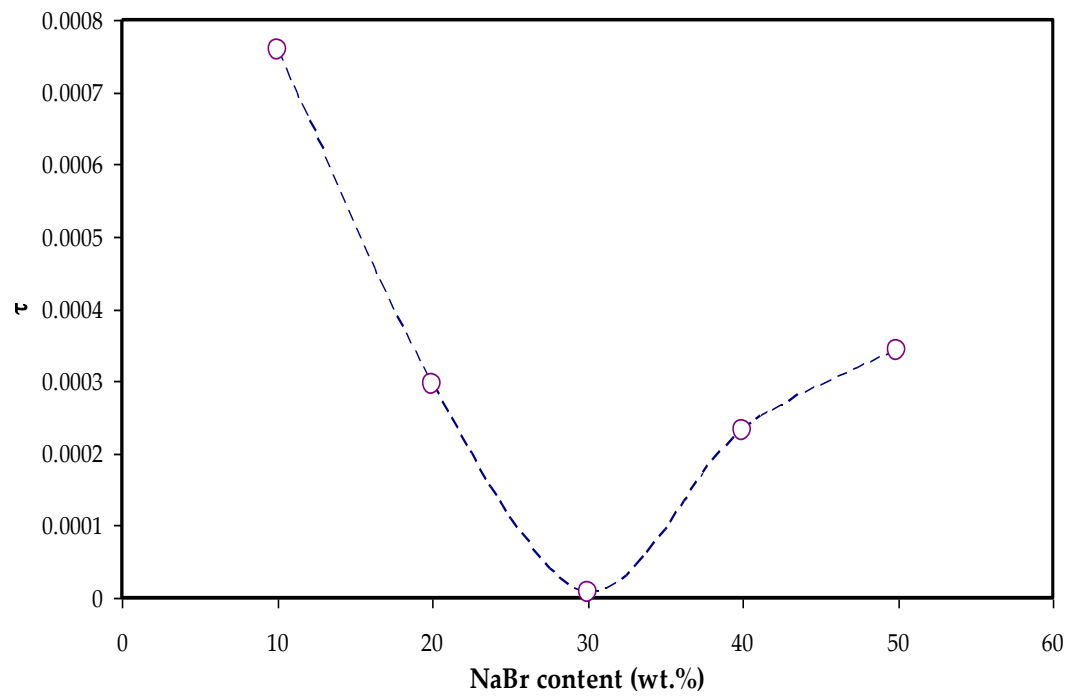

Figure 9. Relaxation time vs. $\mathrm{NaBr}$ concentration.

The relaxation time was observed to decrease as the conductivity increased as given in Table 2 and Figure 9. It is seen in Figure 9 that the relaxation time is increased at $40 \mathrm{wt} . \%$ and $50 \mathrm{wt} . \% \mathrm{NaBr}$, and the conductivity is decreased due to ion association, as seen in Table 2 . This is because the ions are mostly connected to the polymer chains during the polymer segments motion, which facilitates hopping between the conduction sites [52]. The smaller relaxation time for the sample confirms the quicker ion movements through the samples [53]. Vahini et al. [54] mentioned that small relaxation time led to high ionic conductivity.

Rapid ion migration occurs in MC polymer electrolytes. However, the ion aggregations can obstruct the PE's ionic migration at the $40 \mathrm{wt} . \%$ and $50 \mathrm{wt} . \% \mathrm{NaBr}$, thus the relaxation time increases, and the conductivity and dielectric constant are decreased due to ion association. The XRD displayed the increase in the amorphous phase in the $\mathrm{MC}: \mathrm{NaBr}$ films, while some peaks with high intensity appeared in the XRD pattern of MCNAB4 and 
MCNAB55 samples associated with the undissolved salts in these samples. The XRD and EIS results agree as the conductivity decreased for the MCNAB4 and MCNAB5 films.

\subsection{Electric Modulus Study}

The establishment of a relationship between ionic conductivity and relaxation time during analysis is represented by $M^{*}$ [55]. Interestingly, the relaxation phenomena examination by the electric modulus is superior to conductivity relaxationand permittivity treatments. This is due to suppressing the high value of $\epsilon_{r}$ and $\epsilon_{i}$ at the low frequency. Additionally, the difficulties in dielectric spectrum analysis can be fixed by neglecting the injection of absorbed impurityand space charge [56]. Figures 10 and 11 show that the $M_{r}$ and $M_{i}$ values approach zero due to the large capacitance of the double-layer charges at the low-frequency region [16,57]. When the dielectric constant and $M_{r}$ spectra are compared, it is clear that the $M_{r}$ are completely different. The high value is recorded for dielectric constant at low frequency, as exhibited in Figure 5.

In contrast, a minimum value is recorded for electric modules $\left(M_{r}\right.$ and $\left.M_{i}\right)$ at the high frequency, as seen in Figures 10 and 11. This is because the complex electric modules are the reciprocal of the complex dielectric constant. Figure 11 clearly reveals the imaginary part of $M^{*}$ where the peak of the conductivity relaxation is observed. It is perceived that increasing $\mathrm{NaBr}$ cause shifting the relaxation peak to low frequency side, indicating an increase in relaxation time $\left(\tau_{o}=1 / \omega_{\max }\right)$. This means decreasing of segmental mobility in the amorphous phase of the samples with increasing relaxation time. In Figure 11, the responses (peaks) are caused by short-range polymer segmental movement (dipolar mobility) and translational long-range ion movement (translational mobility). In other words, the charges are restricted to potential wells and moving within a short distance at the high frequency range $[58,59]$. In the low frequency region, the peaks result from the dipole molecules reorienting at sufficient time with the polarization and alternating EF. Overall, all these occurrences produce a double capacitance layer between the electrode and electrolyte interface. Thus, increasing dielectric constant values and relatively very low $M_{i}$ values are recorded. On the other hand, the stimulus caused by the ions can only perform local (re-orientation) motion results in responses in the form of peaks at the high frequency side $[60,61]$. There is presence and absence of peaks in $M_{i}$ spectra and in $\epsilon_{i}$, respectively (see Figures 6 and 11). Absence or occurrence of peaks in frequency against imaginary EIS plot is related to the effect of space charge and non-localized conductivity. $M^{\prime \prime}$ plots are beneficial in comprehending the behavior of the system when the relaxation processes are speculated to happen owing to ion movement and the electrode impacts are suppressed $[47,62]$. One more interesting observation is the asymmetric peak maxima in the $M_{i}$ plot that will not be predicted by ideal Debye behavior [63]. In comparison, the $\varepsilon_{i}$ is larger than the $\varepsilon_{r}$ values at the low frequencies as a result of the existence of free charge motion within the materials [64]. It has also been established that dielectric relaxation is primarily interpreted from the dipole reorientation processes of the polymer chains by a peak appearing in $\varepsilon_{i}$ spectra. However, the ionic motion cooperatively leads to the relaxation peak not appearing in the $\varepsilon_{i}$ diagram [65].

Additionally, the $M_{i}$ against $M_{r}$ plot, which is called Argand plot for all the films, is shown in Figure 12. The Argand plot indicates an incomplete semicircle and it is extrapolated to suit all the film curves. This distorted semicircle is usually an indicator for the wide relaxation times in the systems and shows the non-Debye behavior [66]. The conductivity of each electrolyte is determined to be directly affected with the arc radius in the Argand plot in which the smallest arc contributes to a larger value of conductivity [67]. This relation is also associated with the electrolyte resistivity. This is related to Equation (10), as the maximum conducting electrolyte (MCNAB 3) curve is nearer to the origin [18]. 


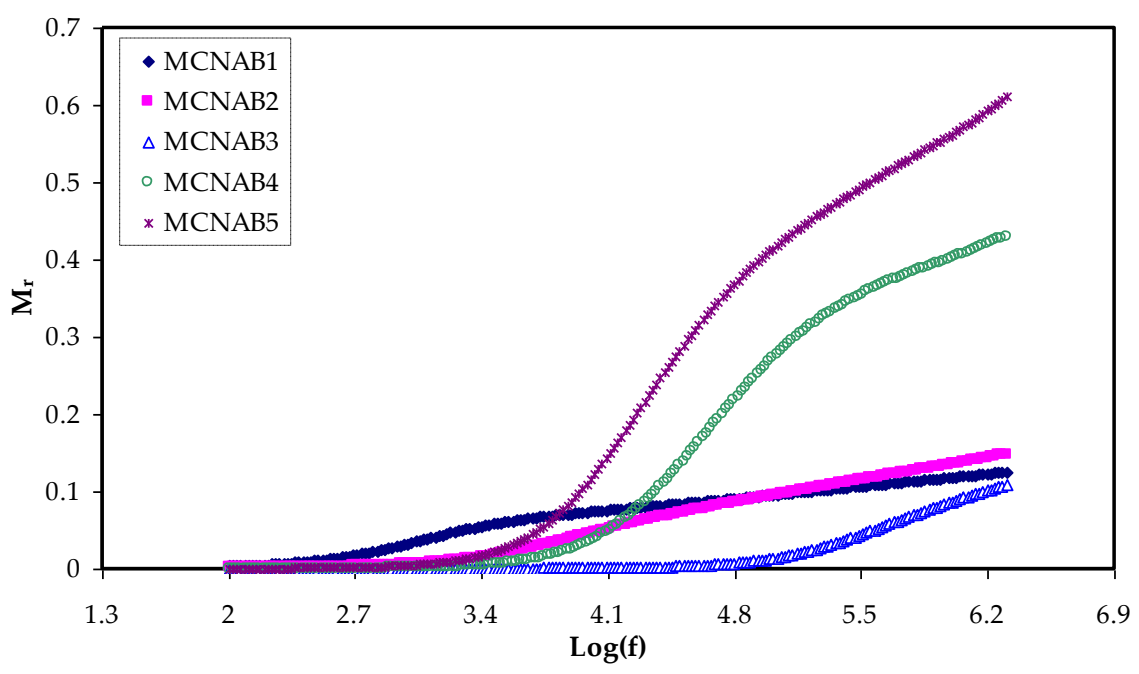

Figure 10. $M_{r}$ against frequency at room temperature for each sample.

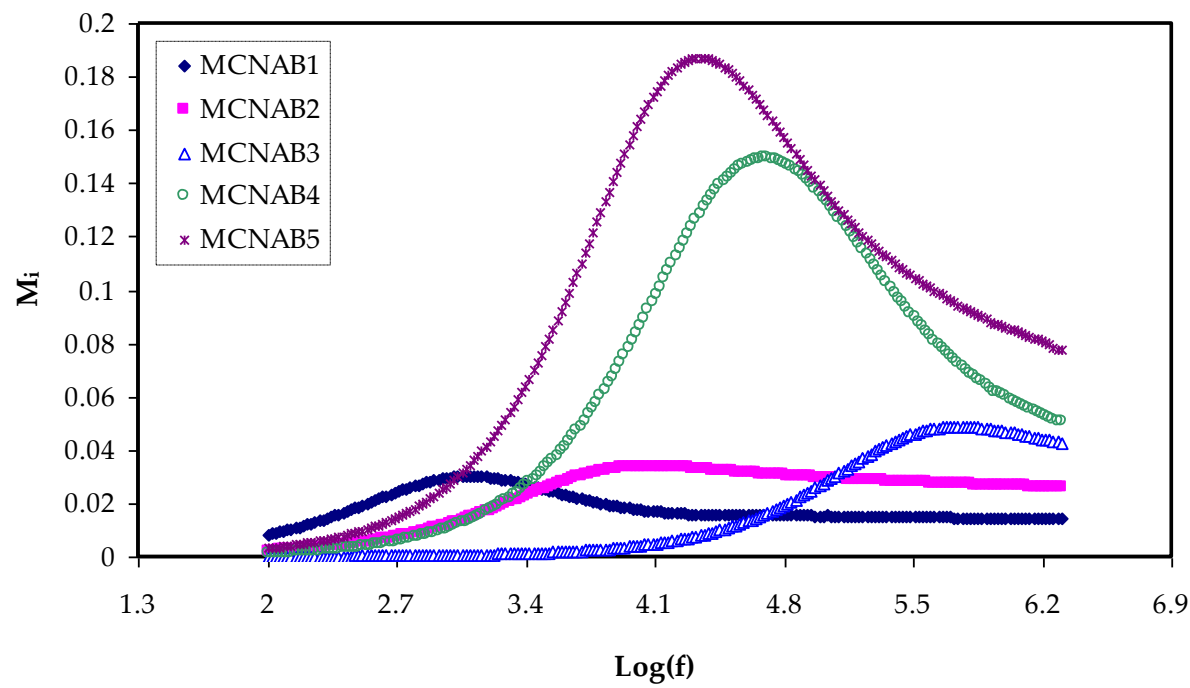

Figure 11. $M_{i}$ against frequency at room temperature for each sample.

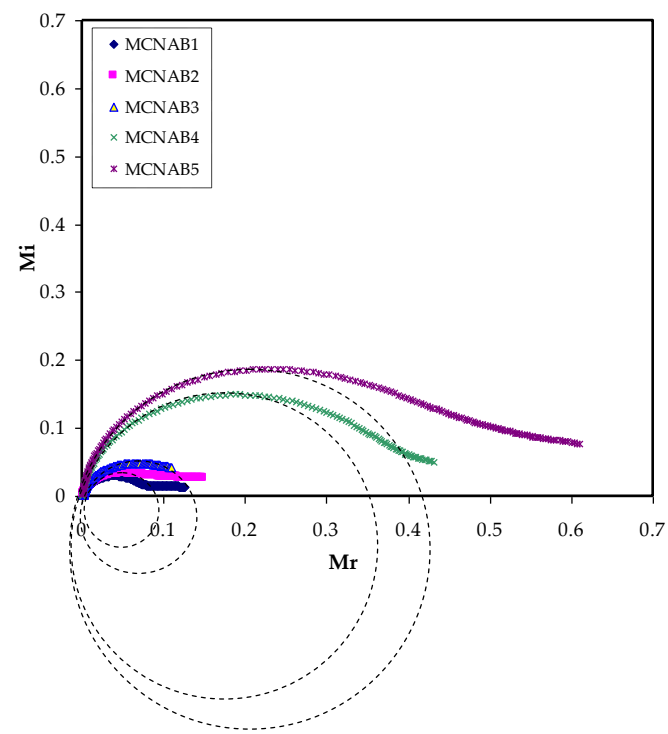

Figure 12. Argand plot at room temperature for each electrolyte. 


\section{Conclusions}

In this work, polymer electrolytes of $\mathrm{MC}$ doped with $\mathrm{NaBr}$ were synthesized using the solution cast technique. FTIR and XRD approaches were used to categorize the structural changes in solid films. At 40 and $50 \mathrm{wt} . \%$ of $\mathrm{NaBr}$, there were sharp crystalline peaks due to protruded salt distinguished at the XRD pattern. The EIS indicated a decrease in bulk resistance up to MCNAB3 sample (30 wt. $\% \mathrm{NaBr}$ ), which shows an increase of carriers. Beyond this concentration, bulk resistance starts increasing. Using EIS, the loading of $\mathrm{NaBr}$ increased the conductivity of the electrolytes. The MCNAB 3 sample obtained a conductivity of $6.71 \times 10^{-6} \mathrm{~S} / \mathrm{cm}$. To acquire extra understanding of the electrical property of the electrolyte films, the EIS data were fitted by the electrical equivalent circuit (EEC). This behavior model was further confirmed by the incomplete semicircle arc presence in the Argand plot. The conductivity of each film is related to its dielectric property. At low frequency, the large dielectric constant value was seen due to electrode polarization. From electric modulus and loss tangent, the extensive nature of the peaks emerged in the tan $\delta$ and electric modulus imaginary parts, showing the distribution of relaxation times. The relaxation time distribution confirms the non-Debye behavior of the electrolytes.

Author Contributions: Conceptualization, S.B.A.; Data curation, B.K.F.; Formal analysis, M.A.B.; A.A.H.; Funding acquisition, O.A.A.A. and D.I.S.; Investigation, S.B.A. and M.A.B.; Methodology, O.A.A.A. and D.I.S.; Project administration, S.B.A., A.M.A., A.A.A. and M.A.B.; Supervision, S.B.A.; Validation, B.K.F., A.A.H., S.B.A., M.A.B., A.M.A., A.A.A., O.A.A.A. and D.I.S.; Writingoriginal draft, S.B.A., B.K.F., A.A.H.; Writing-review and editing, B.K.F., A.A.H., S.B.A., M.A.B., A.M.A., A.A.A., O.A.A.A. and D.I.S. All authors have read and agreed to the published version of the manuscript.

Funding: This research received no external funding.

Institutional Review Board Statement: Not applicable.

Informed Consent Statement: Not applicable.

Data Availability Statement: Not applicable.

Acknowledgments: We would like to acknowledge all support for this work by the University of Sulaimani, Charmo University, and Komar University of Science and Technology. The authors acknowledge the financial support of Taif University Researchers Supporting Project number (TURSP2020/220), Taif University, Taif, Saudi Arabia.

Conflicts of Interest: The authors declare no conflict of interest.

\section{References}

1. Chen, Z.; Pei, J.; Li, R. Study of the Preparation and Dielectric Property of PP/SMA/PVDF Blend Material. Appl. Sci. 2017, 7, 389. [CrossRef]

2. Di Noto, V.; Negro, E.; Lavina, S.; Vittadello, M. Hybrid inorganic-organic polymer electrolytes. In Polymer Electrolytes; Woodhead Publishing: Cambridge, UK, 2010; pp. 219-277. [CrossRef]

3. Asnawi, A.; Hamsan, M.; Aziz, S.; Kadir, M.; Matmin, J.; Yusof, Y. Impregnation of [Emim] Br ionic liquid as plasticizer in biopolymer electrolytes for EDLC application. Electrochim. Acta 2021, 375, 137923. [CrossRef]

4. Aziz, S.; Dannoun, E.; Hamsan, M.; Abdulwahid, R.; Mishra, K.; Nofal, M.; Kadir, M. Improving EDLC Device Performance Constructed from Plasticized Magnesium Ion Conducting Chitosan Based Polymer Electrolytes via Metal Complex Dispersion. Membranes 2021, 11, 289. [CrossRef]

5. Aziz, S.; Nofal, M.; Kadir, M.; Dannoun, E.; Brza, M.; Hadi, J.; Abdullah, R. Bio-Based Plasticized PVA Based Polymer Blend Electrolytes for Energy Storage EDLC Devices: Ion Transport Parameters and Electrochemical Properties. Materials 2021, 14, 1994. [CrossRef]

6. Aziz, S.; Asnawi, A.; Kadir, M.; Alshehri, S.; Ahamad, T.; Yusof, Y.; Hadi, J. Structural, Electrical and Electrochemical Properties of Glycerolized Biopolymers Based on Chitosan (CS): Methylcellulose (MC) for Energy Storage Application. Polymers 2021, 13, 1183. [CrossRef]

7. Ngai, K.S.; Ramesh, S.; Ramesh, K.; Juan, J.C. A review of polymer electrolytes: Fundamental, approaches and applications. Ionics 2016, 22, 1259-1279. [CrossRef]

8. Aziz, S.B. Li+ ion conduction mechanism in poly ( $\varepsilon$-caprolactone)-based polymer electrolyte. Iran. Polym. J. 2013, 22, 877-883. [CrossRef] 
9. Aziz, S.B.; Brza, M.A.; Nofal, M.M.; Abdulwahid, R.T.; Hussen, S.A.; Hussein, A.M.; Karim, W.O. A Comprehensive Review on Optical Properties of Polymer Electrolytes and Composites. Materials 2020, 13, 3675. [CrossRef] [PubMed]

10. Aziz, S.B.; Abidin, Z.H.Z. Electrical and morphological analysis of chitosan: AgTf solid electrolyte. Mater. Chem. Phys. 2014, 144, 280-286. [CrossRef]

11. Agrawal, R.C.; Pandey, G.P. Solid polymer electrolytes: Materials designing and all-solid-state battery applications: An overview. J. Phys. D Appl. Phys. 2008, 41, 223001. [CrossRef]

12. Brza, M.A.; Aziz, S.B.; Nofal, M.M.; Saeed, S.R.; Al-Zangana, S.; Karim, W.O.; Hussen, S.A.; Abdulwahid, R.T.; Kadir, M.F.Z Drawbacks of Low Lattice Energy Ammonium Salts for Ion-Conducting Polymer Electrolyte Preparation: Structural, Morphological and Electrical Characteristics of CS:PEO: $\mathrm{NH}_{4} \mathrm{BF}_{4}$-Based Polymer Blend Electrolytes. Polymers 2020, 12, 1885. [CrossRef]

13. Aziz, S.B.; Brza, M.; Saed, S.R.; Hamsan, M.H.; Kadir, M. Ion association as a main shortcoming in polymer blend electrolytes based on CS:PS incorporated with various amounts of ammonium tetrafluoroborate. J. Mater. Res. Technol. 2020, 9, 5410-5421. [CrossRef]

14. Salehan, S.S.; Nadirah, B.N.; Saheed, M.S.M.; Yahya, W.Z.N.; Shukur, M.F. Conductivity, structural and thermal properties of corn starch-lithium iodide nanocomposite polymer electrolyte incorporated with $\mathrm{Al}_{2} \mathrm{O}_{3}$. J. Polym. Res. 2021, 28, 1-11. [CrossRef]

15. Shetty, S.K.; Ismayil; Shetty, G. Enhancement of Electrical and Optical Properties of Sodium Bromide Doped Carboxymethyl Cellulose Biopolymer Electrolyte Films. J. Macromol. Sci. Part B 2020, 59, 235-247. [CrossRef]

16. Agrawal, S.L.; Singh, M.; Tripathi, M.; Dwivedi, M.M.; Pandey, K. Dielectric relaxation studies on $\left[\mathrm{PEO}^{-S i O}{ }_{2}\right]: \mathrm{NH}_{4} \mathrm{SCN}$ nanocomposite polymer electrolyte films. J. Mater. Sci. 2009, 44, 6060-6068. [CrossRef]

17. Aziz, S.B.; Abidin, Z.H.Z. Ion-transport study in nanocomposite solid polymer electrolytes based on chitosan: Electrical and dielectric analysis. J. Appl. Polym. Sci. 2015, 132, 41774. [CrossRef]

18. Aziz, S.B. Role of Dielectric Constant on Ion Transport: Reformulated Arrhenius Equation. Adv. Mater. Sci. Eng. 2016, 2016, 2527013. [CrossRef]

19. Aziz, S.B.; Abdullah, R.M.; Rasheed, M.A.; Ahmed, H.M. Role of Ion Dissociation on DC Conductivity and Silver Nanoparticle Formation in PVA:AgNt Based Polymer Electrolytes: Deep Insights to Ion Transport Mechanism. Polymers 2017, 9, 338. [CrossRef]

20. Pradhan, D.K.; Choudhary, R.N.P.; Samantaray, B.K. Studies of Dielectric Relaxation and AC Conductivity Behaviorof Plasticized Polymer Nanocomposite Electrolytes. Int. J. Electrochem. Sci. 2008, 3, 597-608.

21. Rao, V.; Ashokan, P.V.; Shridhar, M.H. Studies of dielectric relaxation and a.c. conductivity in cellulose acetate hydrogen phthalate-poly(methyl methacrylate) blends. Mater. Sci. Eng. A 2000, 281, 213-220. [CrossRef]

22. Prokhorov, E.; Luna-Bárcenas, G.; González-Campos, J.; Kovalenko, Y.; García-Carvajal, Z.; Mota-Morales, J. Proton conductivity and relaxation properties of chitosan-acetate films. Electrochim. Acta 2016, 215, 600-608. [CrossRef]

23. Reddy, C.V.S.; Jin, A.-P.; Zhu, Q.-Y.; Mai, L.-Q.; Chen, W. Preparation and characterization of (PVP + NaClO4) electrolytes for battery applications. Eur. Phys. J. E 2006, 19, 471-476. [CrossRef]

24. Fuentes, I.; Andrio, A.; Teixidor, F.; Viñas, C.; Compañ, V. Enhanced conductivity of sodium versus lithium salts measured by impedance spectroscopy. Sodium cobaltacarboranes as electrolytes of choice. Phys. Chem. Chem. Phys. 2017, 19, 15177-15186. [CrossRef]

25. Atkins, P. Shriver and Atkins' Inorganic Chemistry, 5th ed.; W. H. Freeman and Company: New York, NY, USA, 2010; ISBN 978-14292-1820-7.

26. Railanmaa, A.; Kujala, M.; Keskinen, J.; Kololuoma, T.; Lupo, D. Highly flexible and non-toxic natural polymer gel electrolyte for printed supercapacitors for IoT. Appl. Phys. A 2019, 125, 168. [CrossRef]

27. Aziz, S.B.; Rasheed, M.A.; Ahmed, H.M. Synthesis of Polymer Nanocomposites Based on [Methyl Cellulose $]_{(1-x)}:(\mathrm{CuS})_{\mathrm{x}}$ $(0.02 \mathrm{M} \leq x \leq 0.08 \mathrm{M})$ with Desired Optical Band Gaps. Polymers 2017, 9, 194. [CrossRef]

28. Turhan, K.; Sahbaz, F.; Güner, A. A Spectrophotometric Study of Hydrogen Bonding in Methylcellulose-based Edible Films Plasticized by Polyethylene Glycol. J. Food Sci. 2001, 66, 59-62. [CrossRef]

29. Aziz, N.A.N.; Idris, N.K.; Isa, M.I.N. Solid Polymer Electrolytes Based on Methylcellulose: FT-IR and Ionic Conductivity Studies Int. J. Polym. Anal. Charact. 2010, 15, 319-327. [CrossRef]

30. Zhu, Y.; Xiao, S.; Li, M.; Chang, Z.; Wang, F.; Gao, J.; Wu, Y. Natural macromolecule based carboxymethyl cellulose as a gel polymer electrolyte with adjustable porosity for lithium ion batteries. J. Power Sources 2015, 288, 368-375. [CrossRef]

31. Tunç, S.; Duman, O.; Polat, T.G. Effects of montmorillonite on properties of methyl cellulose/carvacrol based active antimicrobial nanocomposites. Carbohydr. Polym. 2016, 150, 259-268. [CrossRef]

32. Buslov, D.K.; Sushko, N.I.; Tretinnikov, O.N. Study of thermal gelation of methylcellulose in water using FTIR-ATR spectroscopy. J. Appl. Spectrosc. 2008, 75, 514-518. [CrossRef]

33. Liu, P.; Wei, X.; Liu, Z. Miscibility Study of Chitosan and Methylcellulose Blends. Adv. Mater. Res. 2013, 750-752, 802-805.

34. Salleh, N.S.; Aziz, S.B.; Aspanut, Z.; Kadir, M.F.Z. Electrical impedance and conduction mechanism analysis of biopolymer electrolytes based on methyl cellulose doped with ammonium iodide. Ionics 2016, 22, 2157-2167. [CrossRef]

35. Pradhan, D.K.; Choudhary, R.N.; Samantaray, B.K.; Karan, N.K.; Katiyar, R.S. Effect of Plasticizer on Structural and Electrical Properties of Polymer Nanocompsoite Electrolytes. Int. J. Electrochem. Sci. 2007, 2, 861-871.

36. Mohapatra, S.R.; Thakur, A.K.; Choudhary, R.N.P. Effect of nanoscopic confinement on improvement in ion conduction and stability properties of an intercalated polymer nanocomposite electrolyte for energy storage applications. J. Power Sources $\mathbf{2 0 0 9}$ 191, 601-613. [CrossRef] 
37. Aziz, S.B.; Abdullah, R.M. Crystalline and amorphous phase identification from the tan $\delta$ relaxation peaks and impedance plots in polymer blend electrolytes based on [CS: AgNt] x:PEO $(x-1)(10 \leq x \leq 50)$. Electrochim. Acta 2018, 285, 30-46. [CrossRef]

38. Aziz, S.B.; Abdullah, R.M.; Kadir, M.F.Z.; Ahmed, H.M. Non suitability of silver ion conducting polymer electrolytes based on chitosan mediated by barium titanate $\left(\mathrm{BaTiO}_{3}\right)$ for electrochemical device applications. Electrochim. Acta 2019, $296,494-507$. [CrossRef]

39. Teo, L.P.; Buraidah, M.H.; Nor, A.F.M.; Majid, S.R. Conductivity and dielectric studies of $\mathrm{Li}_{2} \mathrm{SnO}_{3}$. Ionics 2012, 18, 655-665. [CrossRef]

40. Aziz, S.B.; Karim, W.O.; Brza, M.A.; Abdulwahid, R.T.; Saeed, S.R.; Al-Zangana, S.; Kadir, M.F.Z. Ion Transport Study in CS: POZ Based Polymer Membrane Electrolytes Using Trukhan Model. Int. J. Mol. Sci. 2019, 20, 5265. [CrossRef]

41. Li, C.; Huang, Y.; Feng, X.; Zhang, Z.; Gao, H.; Huang, J. Silica-assisted cross-linked polymer electrolyte membrane with high electrochemical stability for lithium-ion batteries. J. Colloid Interface Sci. 2021, 594, 1-8. [CrossRef]

42. Vani, C.V.; Thanikaikarasan, S.; Mahalingam, T.; Sebastian, P.; Verea, L.E.; Shajan, X.S. Effect of X-ray Irradiation on Dielectric Properties of Polymer Electrolytes Complexed with $\mathrm{LiCF}_{3} \mathrm{SO}_{3}$. J. New Mater. Electrochem. Syst. 2014, 17, 139-145. [CrossRef]

43. Tripathi, S.K.; Gupta, A.; Kumari, M. Studies on electrical conductivity and dielectric behavior of PVdF-HFP-PMMA-NaI polymer blend electrolyte. Bull. Mater. Sci. 2012, 35, 969-975. [CrossRef]

44. Das, S.; Ghosh, A. Ionic conductivity and dielectric permittivity of $\mathrm{PEO}-\mathrm{LiClO}_{4}$ solid polymer electrolyte plasticized with propylene carbonate. AIP Adv. 2015, 5, 027125. [CrossRef]

45. Aziz, S.B.; Woo, T.J.; Kadir, M.; Ahmed, H.M. A conceptual review on polymer electrolytes and ion transport models. J. Sci. Adv. Mater. Devices 2018, 3, 1-17. [CrossRef]

46. Aziz, S.B. Study of electrical percolation phenomenon from the dielectric and electric modulus analysis. Bull. Mater. Sci. 2015, 38, 1597-1602. [CrossRef]

47. Gohel, K.; Kanchan, D. Ionic conductivity and relaxation studies in PVDF-HFP:PMMA-based gel polymer blend electrolyte with $\mathrm{LiClO}_{4}$ salt. J. Adv. Dielectr. 2018, 8, 1850005. [CrossRef]

48. Pawlicka, A.; Tavares, F.C.; Dörr, D.S.; Cholant, C.M.; Ely, F.; Santos, M.J.L.; Avellaneda, C.O. Dielectric behavior and FTIR studies of xanthan gum-based solid polymer electrolytes. Electrochim. Acta 2019, 305, 232-239. [CrossRef]

49. Marf, A.S.; Abdullah, R.M.; Aziz, S.B. Structural, Morphological, Electrical and Electrochemical Properties of PVA: CS-Based Proton-Conducting Polymer Blend Electrolytes. Membranes 2020, 10, 71. [CrossRef]

50. Woo, H.; Majid, S.; Arof, A. Dielectric properties and morphology of polymer electrolyte based on poly $(\epsilon$-caprolactone) and ammonium thiocyanate. Mater. Chem. Phys. 2012, 134, 755-761. [CrossRef]

51. Idris, N.H.; Senin, H.B.; Arof, A.K. Dielectric spectra of LiTFSI-doped chitosan/PEO blends. Ionics 2007, 13, 213-217. [CrossRef]

52. Sengwa, R.; Dhatarwal, P. Predominantly chain segmental relaxation dependent ionic conductivity of multiphase semicrystalline PVDF/PEO/LiClO4 solid polymer electrolytes. Electrochim. Acta 2020, 338, 135890. [CrossRef]

53. Ahmed, H.T.; Jalal, V.J.; Tahir, D.A.; Mohamad, A.H.; Abdullah, O.G. Effect of PEG as a plasticizer on the electrical and optical properties of polymer blend electrolyte MC-CH-LiBF4 based films. Results Phys. 2019, 15, 102735. [CrossRef]

54. Vahini, M.; Muthuvinayagam, M.; Isa, M.I.N.M. Preparation and Characterization of Biopolymer Electrolytes Based on Pectin and NaNO3 for Battery Applications. Polym. Sci. Ser. A 2019, 61, 823-831. [CrossRef]

55. Pradhan, D.K.; Choudhary, R.N.P.; Samantaray, B.K. Studies of structural, thermal and electrical behavior of polymer nanocomposite electrolytes. Express Polym. Lett. 2008, 2, 630-638. [CrossRef]

56. Sengwa, R.J.; Choudhary, S. Investigation of correlation between dielectric parameters and nanostructures in aqueous solution grown poly(vinyl alcohol)-montmorillonite clay nanocomposites by dielectric relaxation spectroscopy. Express Polym. Lett. 2010, 4, 559-569. [CrossRef]

57. Aziz, S.B.; Abidin, Z.H.Z.; Arof, A.K. Influence of silver ion reduction on electrical modulus parameters of solid polymer electrolyte based on chitosan-silver triflate electrolyte membrane. Express Polym. Lett. 2010, 4, 300-310. [CrossRef]

58. Aziz, S.B. Occurrence of electrical percolation threshold and observation of phase transition in chitosan $(1-\mathrm{x})$ :AgIx $(0.05 \leq \mathrm{x} \leq 0.2)$ based ion-conducting solid polymer composites. Appl. Phys. A 2016, 122, 706. [CrossRef]

59. Castillo, J.; Chacon, M.; Castillo, R.; Vargas, R.A.; Bueno, P.R.; Varela, J.A. Dielectric relaxation and dc conductivity on the $\mathrm{PVOH}-\mathrm{CF}_{3} \mathrm{COONH}_{4}$ polymer system. Ionics 2009, 15, 537-544. [CrossRef]

60. Ahmad, M.M. Lithium ionic conduction and relaxation dynamics of spark plasma sintered $\mathrm{Li}_{5} \mathrm{La}_{3} \mathrm{Ta}_{2} \mathrm{O}_{12}$ garnet nanoceramics Nanoscale Res. Lett. 2015, 10, 58. [CrossRef] [PubMed]

61. Aziz, S.B.; Al-Zangana, S.; Woo, H.J.; Kadir, M.F.Z.; Abdullah, O.G. The Compatibility of Chitosan with Divalent Salts over Monovalent Salts for the Preparation of Solid Polymer Electrolytes. Results Phys. 2018, 11, 826-836. [CrossRef]

62. Dave, G.; Kanchan, D.K. Dielectric relaxation and modulus studies of PEO-PAM blend based sodium salt electrolyte system Indian J. Pure Appl. Phys. 2018, 56, 978-988.

63. Aziz, S.B.; Mamand, S.M. The Study of Dielectric Properties and Conductivity Relaxation of Ion Conducting Chitosan: NaTf Based Solid Electrolyte. Int. J. Electrochem. Sci. 2018, 13, 10274-10288. [CrossRef]

64. Malathi, J.; Kumaravadivel, M.; Brahmanandhan, G.; Hema, M.; Baskaran, R.; Selvasekarapandian, S. Structural, thermal and electrical properties of PVA- $\mathrm{LiCF}_{3} \mathrm{SO}_{3}$ polymer electrolyte. J. Non-Cryst. Solids 2010, 356, 2277-2281. [CrossRef] 
65. Pradhan, D.K.; Choudhary, R.; Samantaray, B. Studies of dielectric and electrical properties of plasticized polymer nanocomposite electrolytes. Mater. Chem. Phys. 2009, 115, 557-561. [CrossRef]

66. Gohel, K.; Kanchan, D.K. Effect of PC:DEC plasticizers on structural and electrical properties of PVDF-HFP:PMMA based gel polymer electrolyte system. J. Mater. Sci. Mater. Electron. 2019, 30, 12260-12268. [CrossRef]

67. Sundaramahalingam, K.; Muthuvinayagam, M.; Nallamuthu, N. AC Impedance Analysis of Lithium Ion Based PEO:PVP Solid Polymer Blend Electrolytes. Polym. Sci. Ser. A 2019, 61, 565-576. [CrossRef] 